\title{
APLICAÇÕES DE FIBRAS LIGNOCELULÓSICAS NA QUÍMICA DE POLÍMEROS E EM COMPÓSITOS
}

\author{
Rafael Silva, Shirani K. Haraguchi, Edvani C. Muniz e Adley F. Rubira* \\ Departamento de Química, Universidade Estadual de Maringá, Av. Colombo, 5790, 87020-900 Maringá - PR, Brasil
}

Recebido em 19/1/09; aceito em 25/3/09; publicado na web em 2/4/09

\begin{abstract}
APPLICATIONS OF LIGNOCELLULOSIC FIBERS IN POLYMER CHEMISTRY AND IN COMPOSITES. The use of lignocellulosic fibers and their constituents, as raw materials in the production of polymeric and composite materials, represent an exceptional opportunity of sustainable technological development. In the present report works that discuss promising alternatives of obtaining and use of materials such as cellulose, hemicellulose, lignin, cellulose nanocrystals and biocomposites were revised. The advance in the use of biomass can be, in a near future, capable of going beyond the application difficulties of these vast materials, especially in relation to the economical unviability, by the production of high performance polymeric and composite materials. This advance would represent a higher profitability to some areas of agrobusiness, especially the sector of biofuels, which produces elevated amounts of biomass waste.
\end{abstract}

Keywords: lignocellulosic fibers; nanowhiskers; biocomposites.

\section{INTRODUÇÃO}

Nos últimos anos tem surgido um grande interesse mundial no desenvolvimento de tecnologias "verdes" que possibilitem a utilização de produtos de menor impacto ambiental. ${ }^{1-4}$ A química "verde", como um todo, implica no desenvolvimento de processos químicos e produtos que levem a um ambiente mais limpo, saudável e sustentável. Neste contexto, os materiais plásticos sintéticos têm recebido especial atenção por conter em seus métodos de preparação questões que devem ser priorizadas. As questões que devem ser priorizadas são a não-biodegradabilidade dos plásticos sintéticos e por serem oriundos de fontes não-renováveis. ${ }^{5-8}$

$\mathrm{Na}$ busca pela sustentabilidade, várias pesquisas e trabalhos na área de materiais poliméricos e compósitos foram, e estão sendo, realizados para garantir a preservação ambiental e proporcionar um melhor padrão de vida à sociedade. ${ }^{9-13}$ Dentre as pesquisas nesta área, as que buscam a aplicação de recursos naturais na preparação dos materiais vêm crescendo, podendo-se destacar o uso de fibras naturais. ${ }^{14-22}$

A Organização das Nações Unidas para a Agricultura e a Alimentação (FAO-ONU - Food and Agriculture Organization of the United Nations) declarou o ano de 2009 como o ano internacional das fibras naturais. ${ }^{23}$ A medida visa conscientizar e estimular a utilização de fibras naturais, encorajando políticas governamentais de incentivo ao setor e às ações empresariais sustentáveis, para a exploração dessas matérias-primas.

Destaque ainda maior deve ser dado à utilização de fibras naturais de origem vegetal, em razão da enorme variedade de espécies passíveis de serem pesquisadas. Diversas fibras vegetais são produzidas em praticamente todos os países e usualmente são designadas como materiais lignocelulósicos. Algumas fibras ocorrem espontaneamente na natureza, outras são cultivadas como atividade agrícola e ainda há aquelas que são resíduos gerados, principalmente, pela agroindústria. Na Tabela 1 pode ser verificada a produção anual das principais culturas brasileiras que geram fibras lignocelulósicas de forma direta ou indireta, ${ }^{24}$ sendo que a forma indireta se refere à produção de fibras como rejeitos ou subproduto da cultura. O potencial produtivo de fibras lignocelulósicas no Brasil, assim como o seu mercado, métodos

\footnotetext{
*e-mail: afrubira@uem.br
}

de extração, características morfológicas, propriedades e aplicações comuns foram discutidos por Satyanarayana e colaboradores. ${ }^{25}$

A agroindústria gera inúmeras fontes de biomassa que não são satisfatoriamente e/ou adequadamente aproveitadas, transformandoas em rejeitos industriais. O setor de produção de biocombustíveis, como etanol e biodiesel, está entre os segmentos da agroindústria que mais geram biomassa como rejeito ${ }^{26} \mathrm{~A}$ produção de álcool a partir da cana-de-açúcar tem sido considerada, em escala mundial, como uma forma viável de produção de um possível combustível substituto dos combustíveis derivados de petróleo. De acordo com Lora e Andrade, ${ }^{27}$ no Brasil, há 325 indústrias de álcool/açúcar que processam 426,6 milhões de toneladas de cana-de-açúcar por ano, gerando 121,15 milhões de toneladas de bagaço e palha. Em média, cada tonelada de cana-de-açúcar produz $150 \mathrm{~kg}$ de açúcar, $140 \mathrm{~kg}$ de bagaço e $140 \mathrm{~kg}$ de palha. Assim, a viabilidade econômica da produção de álcool pode ser otimizada agregando valor aos resíduos industriais oriundos do seu processo de produção. Na cadeia produtiva do biodiesel também é gerado material lignocelulósico residual (palha, tronco, galhos, cascas e bagaço) proveniente das espécies oleaginosas como, por exemplo, soja, canola, mamona e algodão, ${ }^{28}$ entre outras ${ }^{29}$, das quais é extraído o óleo vegetal, principal matéria-prima do biodiesel.

A utilização de etanol e glicerina, subprodutos da cadeia produtiva do biodiesel, para a produção de polímeros "verdes" irá impulsionar a produção de biomassa residual. Algumas empresas já dominam o processo de conversão de etanol em polietileno e de glicerina em polipropileno ou poli(cloreto de vinila). Nos próximos anos, grandes empresas petroquímicas como Braskem, Dow Brasil, Nova Petroquímica e Solvay irão começar a produção destes polímeros "verdes" no Brasil, com investimentos superiores a US\$ 1,3 bilhões. ${ }^{30}$

A elevada disponibilidade de fibras lignocelulósicas, somada à necessidade de uma fonte renovável para a produção de polímeros, abre uma grande oportunidade para avanços tecnológicos que agreguem valor aos produtos da agroindústria e, ao mesmo tempo, atuem na fixação de carbono na natureza. Isso implica auxiliar na redução da emissão de $\mathrm{CO}_{2}$ na atmosfera durante o ciclo de produção, processamento e utilização de produtos da agroindústria, aumentando o potencial econômico do agronegócio em virtude da possibilidade de comércio de créditos de carbono para a cadeia produtiva, que surgiu em consequência do mecanismo de desenvolvimento limpo previsto no Protocolo de Kyoto. ${ }^{31}$ 
Tabela 1. Produção anual de culturas diretas ou indiretas de fibras lignocelulósicas no Brasil

\begin{tabular}{lcccc}
\hline Cultura & \multicolumn{3}{c}{ Produção Anual (mil toneladas) } \\
\cline { 2 - 5 } & 2004 & 2005 & 2006 & 2007 \\
\hline Juta (fibra) & 2 & 6 & 4 & 6 \\
Malva (fibra) & 10 & 20 & 14 & 20 \\
Rami (fibra) & 1 & 1 & - & 248 \\
Sisal (fibra) & 199 & 207 & 2.884 & 3.661 \\
Algodão herbáceo (em caroço) & 3.798 & 3.666 & 1.857 & 2.017 \\
Coco-da-baía* & 2.078 & 2.079 & 1.658 & 1.682 \\
Abacaxi* & 1.477 & 1.528 & 457.984 & 489.957 \\
Cana-de-açúcar & 415.206 & 422.957 & 11.505 & 11.045 \\
Arroz (em casca) & 13.277 & 13.193 & \\
\hline
\end{tabular}

*Produção anual em milhões de frutos. Fonte: Ministério da Agricultura ${ }^{24}$

O campo de emprego das fibras naturais é bastante amplo, abrangendo desde as aplicações clássicas na indústria têxtil até o reforço de matrizes poliméricas termoplásticas e termofixas. Recentemente, a utilização de fibras naturais como materiais absorventes de metais pesados no tratamento de resíduos industriais tem sido apresentada como uma alternativa de uso para as fibras naturais. ${ }^{32-39}$ Por razões técnicas e comerciais, também, a indústria automotiva começou a usar compósitos com fibras vegetais, sendo esta uma tendência mundial. Há alguns anos, várias empresas do segmento automotivo têm aplicado diferentes fibras na produção de seus carros, estando entre as mais utilizadas as fibras de sisal, coco, juta e carauá. ${ }^{40}$ As fibras vegetais aparecem, então, como uma valiosa alternativa às fibras inorgânicas.

O uso de fibras naturais na indústria automotiva, além de substituir recursos não-renováveis, possibilita a fabricação de peças mais leves e mais seguras, pois esses materiais não geram arestas cortantes ao serem rompidas; têm excelentes propriedades físico-mecânicas, sendo equivalentes, ou até mesmo superiores, às dos compósitos convencionais e, possuem custos bem menores. ${ }^{41-44}$ As fibras vegetais são menos abrasivas que as fibras inorgânicas usualmente utilizadas como reforço (por exemplo, fibra de vidro) e assim geram menor desgaste dos equipamentos envolvidos em seu processamento. ${ }^{21,45}$ Além disso, são materiais biodegradáveis, característica crucial para componentes que, uma vez tendo esgotado sua vida útil, podem ser descartados. ${ }^{11}$

A indústria automobilística brasileira tem se destacado no segmento de produção de peças com fibras vegetais, sendo um bom exemplo disso a utilização de fibras obtidas do coco verde. A metodologia de beneficiamento do coco verde foi desenvolvida por pesquisadores da EMBRAPA, ${ }^{46}$ pois até então, apenas as fibras de coco maduro eram utilizadas. Atualmente, existem várias empresas brasileiras de pequeno e médio porte que adquirem as fibras de coco de pequenas cooperativas para a produção de materiais compósitos com o látex. Uma destas empresas é a POEMATEC, que atua no estado do Pará; esta empresa surgiu do POEMA (Programa Pobreza e Meio Ambiente na Amazônia, um programa de pesquisa e desenvolvimento da Universidade Federal do Pará). A POEMATEC usa um compósito de látex e fibra de coco para a fabricação de assentos e parassois, entre outras peças que são comercializadas para grandes empresas do segmento automotivo como, por exemplo, a DaimlerChrysler e a Volkswagen. ${ }^{47,48}$ A produção mensal de compósitos da POEMATEC é de aproximadamente 20 toneladas. ${ }^{47}$

As vantagens da utilização das fibras naturais em detrimento às fibras sintéticas vão além da melhoria nas propriedades físicas. Sua utilização gera um maior número de empregos ${ }^{49}$ em áreas de baixo índice de desenvolvimento humano como, por exemplo, na região do semiárido da Bahia, região que possui condições adequadas para a produção de sisal, cultura na qual o Brasil é um dos líderes mundiais de produção. ${ }^{23}$

Atualmente, o estágio de desenvolvimento científico e tecnológico na área de compósitos de madeira e plásticos sintéticos WPC (Wood Plastic Composite) é bem avançado, ${ }^{50,51}$ e sua utilização tem demonstrado vantagens notadas por várias empresas, tais como a Solvay e a Braskem, que têm lançado produtos para diversos fins. Os materiais resultantes da mistura entre madeira e plástico são utilizados para a fabricação de produtos de design interno e externo como, por exemplo, rodapés, cadeiras, decks e corrimãos, entre uma infinidade de outros produtos. ${ }^{52}$

As fibras lignocelulósicas são excelentes matérias-primas para a química de polímeros e compósitos, o que pode ser comprovado pelo elevado número de patentes nacionais e internacionais e o elevado número de produtos já comercializados. A utilização das fibras lignocelulósicas como reforço em materiais poliméricos é uma atividade econômica em franco desenvolvimento, com conhecimento científico e tecnológico parcialmente transferido ao setor produtivo. ${ }^{52}$ Mas, o que vem merecendo mais atenção da comunidade científica é a intensificação da utilização de fibras lignocelulósicas para o desenvolvimento de polímeros e compósitos que aproveitem, em sua totalidade, as características únicas das várias matrizes lignocelulósicas existentes.

No Brasil existem vários grupos de pesquisa que trabalham com fibras lignocelulósicas para a obtenção de compósitos. Segundo Satyanarayana e colaboradores ${ }^{25}$ no Brasil, $12 \%$ dos grupos de pesquisa em engenharia de materiais realizam trabalhos com fibras lignocelulósicas. Mas, no cenário brasileiro existe uma dificuldade para identificar grupos de pesquisa com atuação contínua vinculada às empresas. Além disso, existe uma séria limitação, por não dizer ausência, de grupos de pesquisa com número expressivo de trabalhos científicos nas áreas que serão discutidas na presente contribuição. A formação de vínculos entre universidade e empresas é um fator primordial para o desenvolvimento de pesquisas aplicadas, uma vez que esta possibilita às empresas o acesso aos conhecimentos teóricos e à estrutura física das universidades e, ao mesmo tempo, permite que os pesquisadores tenham acesso aos problemas do setor produtivo.

Neste contexto, o presente trabalho apresenta uma discussão sobre os constituintes principais das fibras lignocelulósicas, sua organização, separação e purificação, modificação química dos constituintes isolados para a formação de polímeros termoplásticos, obtenção de nanocristais de celulose e formação de nanocompósitos, bem como a formação de biocompósitos, que se refere aos compósitos entre fibras 
lignocelulósicas e polímeros biodegradáveis. A relevância científica dos temas discutidos no trabalho pode ser constatada pelo número expressivo de artigos científicos publicados, nos últimos anos, em renomadas revistas da área de polímeros e materiais. No entanto, o fato de não haver, ainda, patentes nacionais e de haver um número muito reduzido de patentes internacionais, indica ser o estudo desses materiais uma excelente oportunidade para o desenvolvimento de novos produtos e processos.

\section{FIBRA LIGNOCELULÓSICA}

As reações de fotossíntese durante a produção de biomassa convergem para a formação de alguns componentes chaves, tais como a celulose e a hemicelulose, os quais consistem de vários carboidratos polimerizados..$^{53}$ As fibras vegetais podem ser consideradas como compósitos de fibrilas de celulose mantidas coesas por uma matriz constituída de lignina e hemicelulose ${ }^{54}$ cuja função é agir como barreira natural à degradação microbiana e servir como proteção mecânica. Suas características estruturais estão relacionadas à natureza da celulose e à sua cristalinidade.

Os principais componentes das fibras vegetais são celulose, hemicelulose e lignina. Além destes componentes são encontrados compostos inorgânicos e moléculas extraíveis com solventes orgânicos, como pectinas, carboidratos simples, terpenos, alcaloides, saponinas, polifenólicos, gomas, resinas, gorduras e graxas, entre outros. ${ }^{43,55}$ As plantas lenhosas típicas são constituídas de $40-50 \%$ de celulose, $20-30 \%$ de hemicelulose e $20-28 \%$ de lignina, além de outras substâncias em menores teores. ${ }^{56}$

\section{Organização das fibras e fibrilas}

A organização mais comum de uma fibra vegetal está representada na Figura 1. Cada fibra lignocelulósica tem uma estrutura de camadas complexas; constituída por uma parede primária fina,

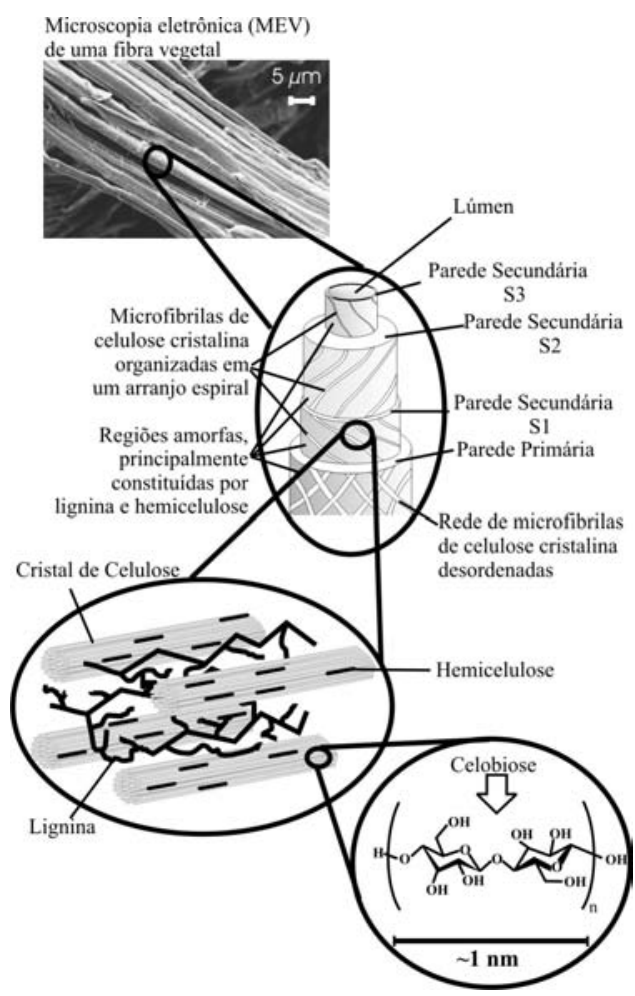

Figura 1. Estrutura de uma fibra vegetal. A imagem de MEV se refere à fibra de Eucalipto inicialmente depositada durante o crescimento das células, que circunda uma parede secundária. A parede secundária é constituída por três camadas (S1, S2 e S3), onde a camada intermediária (S2) determina as propriedades mecânicas da fibra e consiste em uma série de microfibrilas, helicoidalmente formadas por longas cadeias de celulose e organizadas no sentido da fibra. Tais microfibrilas têm o diâmetro de 10 a $30 \mathrm{~nm}$ e são resultantes do empacotamento de 30 a 100 cadeias de celulose estendidas..$^{57,58}$

\section{Celulose}

A celulose é o material orgânico mais abundante na terra, com uma produção anual de mais de 50 bilhões de toneladas. ${ }^{43} \mathrm{~A}$ unidade repetitiva da celulose é composta por duas moléculas de glicose eterificadas por ligações $\beta$-1,4-glicosídicas. Esta unidade repetitiva, conhecida como celobiose, contém seis grupos hidroxila que estabelecem interações do tipo ligações de hidrogênio intra e intermolecular. Devido a essas ligações de hidrogênio há uma forte tendência de a celulose formar cristais que a tornam completamente insolúvel em água e na maioria dos solventes orgânicos.

O grau de cristalinidade da celulose varia de acordo com sua origem e processamento. A celulose de algodão possui cadeias mais ordenadas, apresentando cristalinidade de aproximadamente $70 \%$, enquanto a celulose de árvores apresenta índice de cristalinidade ao redor de $40 \%{ }^{43}$

\section{Hemicelulose}

O termo hemicelulose é usado para os polissacarídeos que ocorrem normalmente associados à celulose, em paredes celulares. ${ }^{59} \mathrm{~A}$ hemicelulose consiste de vários monossacarídeos polimerizados, incluindo carboidratos de cinco carbonos (como xilose e arabinose), carboidratos de seis carbonos (como galactose, glucose e manose), ácido 4-O-metil glucurônico e resíduos de ácido galactorônico. A unidade mais abundante na hemicelulose, em vegetais lenhosos, é a xilose, que se une por ligações glicosídicas nas posições 1 e 4 . A hemicelulose é bastante hidrofílica, contém considerável grau de ramificação entre suas cadeias, com natureza altamente amorfa e DP (Degree of Polimerization) variando entre menos de 100 a no máximo $200 .{ }^{60}$

\section{Lignina}

A lignina está associada com a celulose e a hemicelulose na composição de materiais lignocelulósicos. A lignina é um material hidrofóbico com estrutura tridimensional, altamente ramificada, podendo ser classificada como um polifenol, o qual é constituído por um arranjo irregular de várias unidades de fenilpropano que pode conter grupos hidroxila e metoxila como substituintes no grupo fenil.

As ligações éteres dominam a união entre as unidades da lignina, que apresenta um grande número de interligações. Esta resina amorfa atua como um cimento entre as fibrilas e como um agente enrijecedor no interior das fibras. A força de adesão entre as fibras de celulose e a lignina é ampliada pela existência de ligações covalentes entre as cadeias de lignina e os constituintes da celulose e da hemicelulose. Existe uma grande dificuldade na elucidação química da estrutura da lignina devido ao fato de não haver um método bem estabelecido para isolar a lignina em sua forma nativa. ${ }^{61}$

\section{FRACIONAMENTO E PURIFICAÇÃO DAS FIBRAS EM SEUS CONSTITUINTES}

O estudo dos processos de fracionamento das fibras se faz necessário por possibilitar a utilização dos componentes estruturais 
isolados das fibras vegetais em aplicações específicas. A separação das fibras naturais em seus constituintes principais pode ser realizada por vários métodos, os quais exploram as diferenças químicas e estruturais entre os componentes.

\section{Celulose}

A obtenção de celulose, a partir dos mais diversos tipos de matrizes lignocelulósicas, envolve uma série de processos que têm como principal objetivo o isolamento das fibras de celulose. Isto é realizado por meio do desmembramento do complexo lignina-celulose-poliose por técnicas de pré-tratamento e deslignificação sem a destruição das fibrilas celulósicas, método esse usualmente conhecido por polpação. Na polpação, a lignina e a hemicelulose são seletivamente removidas da fibra por métodos térmicos, químicos, físicos, biológicos ou por combinações destes, dependendo do grau de separação requerido e do fim a que se destina o processo. ${ }^{62}$

O processo de produção de polpa celulósica mais difundido é o processo químico $\mathrm{Kraft}$, que envolve o cozimento da matéria-prima com uma solução contendo hidróxido e sulfeto de sódio, utilizando temperaturas em torno de $160^{\circ} \mathrm{C}$. Este processo possibilita a remoção de grande parte da lignina presente na matriz lignocelulósica, principalmente por meio das reações de clivagens das ligações $\alpha$-aril éter e $\beta$-aril éter feitas pelos ânions hidróxido e hidroxissulfeto que clivam a macromolécula de lignina em fragmentos menores e solúveis nos meios aquoso e alcalino. Em geral, as polpas de celulose resultantes da polpação apresentam coloração escura, sendo necessária a utilização de processos de branqueamento para atingir maiores níveis de alvura, sem que haja perda das propriedades físico-mecânicas da polpa de celulose. ${ }^{63}$

A obtenção de polpas branqueadas e com alto nível de deslignificação pode ser obtida por processos TCF (Totally Chlorine-Free), que utilizam fortes agentes oxidantes e produzem um impacto ambiental menor, se comparado às sequências com cloro. Segundo a revisão de Brasileiro e colaboradores, ${ }^{62}$ os perácidos, especialmente o ácido peracético e o ácido permonossulfúrico (Ácido de Caro), são atualmente considerados ótimos substitutos para os reagentes clorados, por serem espécies altamente oxidantes e por apresentarem vantagens sobre outros reagentes não clorados, tais como peróxido de hidrogênio e ozônio. Estes reagentes permitem a produção de polpas de celulose de maior resistência e maiores índices de deslignificação, promovendo assim menores reversões de alvura após o branqueamento e diminuindo a degradação da celulose. ${ }^{64-66}$ Além disso, perácidos têm sido empregados com sucesso em sequências de deslignificação-branqueamento de alto rendimento junto a tratamento alcalino, especialmente com $\mathrm{NaOH}, \mathrm{KOH}$ ou $\mathrm{NH}_{4} \mathrm{OH}^{67-70}$

Khristova e colaboradores, ${ }^{71}$ empregando sulfito em meio alcalino $\left(\mathrm{NaOH} / \mathrm{Na}_{2} \mathrm{SO}_{3}\right.$ ) em uma sequência de deslignificação-branqueamento TCF para a obtenção da polpa celulósica, demonstraram que a qualidade da polpa de celulose, utilizando o método do sulfito, é superior aos métodos que utilizam apenas meio alcalino na deslignificação.

Um processo de polpação do bagaço da cana-de-açúcar com ácido peroxifórmico, seguido de branqueamento em dois estágios combinando fotocatálise e fotossensibilização, foi demonstrado por Castellan e colaboradores. ${ }^{72} \mathrm{O}$ primeiro estágio consiste na irradiação da polpa em meio alcalino em suspensão aquosa, empregando lâmpadas de tungstênio ou mercúrio, em presença de $\mathrm{TiO}_{2}$, usando como agente fotocatalisador, azul de metileno (MB), ácido 3,4,9,10-perilenotetracarboxílico ou 4,4'4",4"',-tetra-sulfotalocianina de Fe(II) (TSPC) (concentração $\approx 10^{-5} \mathrm{~mol} \mathrm{~L}^{-1}$ ), e como agentes fotossensibilizadores, oxigênio e peróxido de hidrogênio. O segundo estágio, conduzido sob peróxido de hidrogênio, completa eficientemente a deslignificação, permitindo a obtenção de elevado grau de alvura, bem como a remo- ção completa do fotossensibilizador absorvido sobre a polpa.

Outro processo de polpação do bagaço da cana-de-açúcar foi apresentado por Sun e colaboradores ${ }^{73}$ utilizando tratamentos sequenciais de hidróxido de sódio e peróxido de hidrogênio em meio alcalino e o tratamento com ácido acético 80\%/ácido nítrico $70 \%$ $(10: 1, \mathrm{v} / \mathrm{v})$ à alta temperatura. Os rendimentos de celulose pura obtidos com tratamentos sequenciais de hidróxido de sódio e peróxido de hidrogênio em meio alcalino são da mesma ordem de grandeza que o método que utiliza clorito de sódio acidificado.

O caráter altamente recalcitrante das fibras vegetais pode ser sensivelmente atenuado por diferentes processos de pré-tratamento, como revisado por Hendriks e Zeeman. ${ }^{74}$ A modificação estrutural, observada na parede celular da fibra em decorrência do pré-tratamento, resulta da hidrólise parcial da hemicelulose, deixando um resíduo celulósico fibroso do qual a lignina pode ser mais facilmente extraída. O pré-tratamento de materiais lignocelulósicos com vapor de água foi revisado por Ramos, ${ }^{75}$ que apresentou uma boa discussão das alterações causadas pelo tratamento com vapor em fibras de lignocelulose e as vantagens obtidas neste processo.

Os derivados poliméricos da celulose têm um longo histórico industrial. ${ }^{76} \mathrm{O}$ nitrato de celulose foi o primeiro material polimérico termoplástico e foi desenvolvido para aplicações diversas em substituição a diferentes matérias-primas, tais como madeira, metais e marfim, entre outros. ${ }^{77} \mathrm{~A}$ estrutura rígida da celulose tem sido utilizada desde 1920 para produzir o Cellophane ${ }^{\circledast}$; que revolucionou a tecnologia de embalagens, sendo esta a primeira embalagem transparente que possui estabilidade dimensional, permeabilidade a vapores de água e alta biodegradabilidade. ${ }^{78}$ Pelo ponto de vista atual, o Cellophane ${ }^{\circledast}$ não é muito viável por razões econômicas e por algumas questões inerentes a sua produção, caso contrário, a indústria o teria como um material altamente atrativo. Em virtude destes problemas, o emprego do Cellophane ${ }^{\circledast}$ foi quase totalmente substituído no início da década de 70 por plásticos sintéticos.

A transformação da celulose cristalina em um material termoplástico é realizada por substituições e modificações parciais dos grupos hidroxilas presentes na celobiose, introduzindo uma redução das interações intramoleculares entre as cadeias de celulose. ${ }^{79} \mathrm{~A}$ conversão de celulose em polímeros termoplásticos pode ser abordada por diferentes vias, como a modificação das fibras com alto grau de substituição usando substituintes de baixo volume molecular, ou a modificação das cadeias de celulose com baixo grau de substituição usando substituintes de elevado volume molecular e/ou longas cadeias que, em ambos os casos, dificultam o empacotamento das cadeias de celulose. ${ }^{80}$

A produção do acetato de celulose é conhecida deste o século XIX, mas, ainda hoje, a otimização desta reação é de grande interesse. $\mathrm{O}$ acetato de celulose pode ser obtido por diferentes reações de acetilação da polpa de celulose. Heinze e Liebert ${ }^{81}$ reportaram as variações estruturais do acetato de celulose em função de diferentes métodos de produção, correlacionando as propriedades do material final com suas características estruturais.

Algumas técnicas de polimerização viva podem ser utilizadas para enxertar cadeias laterais à celulose. Barsbay e colaboradores ${ }^{82}$ utilizaram a técnica de polimerização de transferência reversível de cadeia por adição-fragmentação RAFT (Reversible Addition-Fragmentation Chain Transfer) para a enxertia de poliestireno em celulose. As metodologias de polimerização viva podem ser exploradas para a enxertia de diferentes polímeros vinílicos na cadeia de celulose, além de possibilitar o controle do tamanho das cadeias laterais e do grau de substituição. ${ }^{83}$

A modificação da celulose pode acarretar diminuição da biodegradabilidade, assim, as pesquisas mais recentes têm convergido para a utilização de modificadores inerentemente biodegradáveis como, 
por exemplo, a caprolactona. A enxertia de caprolactona é facilitada em acetato de celulose, como demonstrado por Számel e colaboradores. ${ }^{84,85}$ A modificação do acetato de celulose com caprolactona resulta na diminuição da dureza e da resistência, mas a deformabilidade é ligeiramente aumentada. A caracterização das propriedades térmicas de caprolactona, polimerizada a partir dos grupos hidroxila do acetato de celulose, foi realizada por Hatakeyama e colaboradores ${ }^{86}$ que analisaram o efeito da associação das cadeias laterais de policaprolactona sobre as propriedades térmicas e viscoelásticas do material.

A inserção de moléculas como N,N-diciclo-hexilcarbodiimida, N,N-carbonildiimidazol e cloreto de p-toluenossulfonil, à cadeia de celulose foi revisada por Heinze e Liebert. ${ }^{87}$ Estas reações ocorrem principalmente utilizando o mecanismo da substituição das hidroxilas da celobiose. Segundo os autores, as atividades de pesquisa e o desenvolvimento de novos conceitos e vias de modificações têm sido devotadas, principalmente, à ativação da celulose e ao controle da reatividade dos reagentes. A ativação da celulose tem como objetivo tornar os grupos hidroxila acessíveis aos agentes modificadores e tem sido realizada pela dissolução da celulose sem a modificação dos grupos hidroxila da celobiose; dissolução após funcionalização parcial dos grupos, com e sem o isolamento dos intermediários em solventes orgânicos comuns ou, pelo intumescimento do material nativo.

A dissolução sem modificação dos grupos hidroxila pode ser utilizada em meio aquoso ou não-aquoso. Soluções de complexos inorgânicos de metais de transição, utilizando aminas ou amônia como ligantes, são capazes de dissolver a celulose. ${ }^{88-91}$ Soluções de $\mathrm{NaOH}$ a $10 \%$ podem dissolver a celulose, mas esta dissolução é restrita aos componentes de menor massa molar, cujo valor de grau de polimerização é de no máximo $200 .{ }^{92,93}$ Sais inorgânicos hidratados e fundidos têm ganhado atenção como novos meios para a dissolução e modificação da celulose. Alguns sais hidratados de lítio (acetato, iodeto, nitrato e perclorato) podem dissolver celulose com valor de DP de até $1500 .{ }^{94,95} \mathrm{~A}$ dissolução de celulose em $\mathrm{N}$-metil-morfolina-N-óxido (NMMO) pode ser realizada na faixa de temperatura entre 85 a $130{ }^{\circ} \mathrm{C} .^{81,96}$

Soluções de $\mathrm{NaOH} /$ ureia, $\mathrm{NaOH} /$ tioureia e $\mathrm{LiOH} /$ ureia têm sido utilizadas para dissolver celulose em temperatura baixa. ${ }^{97-101}$ Estes solventes são atraentes porque a celulose pode ser fácil e rapidamente dissolvida, produzindo soluções de celulose estável que podem ser usadas na preparação de membranas, por exemplo. ${ }^{102,103}$

A utilização de solventes não-aquosos possibilita o uso de grupos sensíveis à umidade, os quais são adequados para a produção de uma série de derivados. O sistema N,N-dimetilacetamida (DMA)/ $\mathrm{LiCl}$ apresenta grande potencial de uso em temperaturas ao redor de $150{ }^{\circ} \mathrm{C} .{ }^{104} \mathrm{O}$ DMA pode ser substituído por outros solventes ou misturas de solventes, como o N-metil-2-pirrolidona (NMP), $\mathrm{N}, \mathrm{N}$-dimetilformamida (DMF), dimetilsulfóxido (DMSO), Ndimetilpiridina e o hexametilfosfórico triamida. Ainda assim, o DMA demonstra ser o solvente que causa os menores efeitos de degradação das cadeias. ${ }^{105-107}$ Recentemente, vários líquidos iônicos têm demonstrado capacidade de dissolver celulose, ${ }^{108,109}$ tais como o cloreto de 1-butil-3-metilimidazol em temperaturas entre 85 a $100{ }^{\circ} \mathrm{C} .{ }^{110,111}$ Além de possibilitar a dissolução da celulose, os líquidos iônicos são ótimos meios reacionais, como demonstrado por Granström e colaboradores ${ }^{112}$ que realizaram a acetilação e tosilação da celulose. As reações podem ser otimizadas para estes solventes com o intuito de obter diferentes derivados com alto rendimento, homogeneidade e grau de substituição. A dissolução e a modificação de celulose em líquidos iônicos foram revisadas por Feng e Chen. ${ }^{113}$

\section{Hemicelulose}

Em virtude da estrutura complexa das fibras vegetais e da integração das estruturas poliméricas ao nível de macromoléculas indi- viduais existem muitas dificuldades na separação dos constituintes minoritários em frações discretas. Durante o processo de polpação, a hemicelulose, dependendo do processo empregado, é completa ou parcialmente degradada junto com a matriz de lignina. ${ }^{114,115}$ Esta é a razão primordial que limita a exploração das características químicas e estruturais da hemicelulose em trabalhos científicos e tecnológicos.

A preparação e as propriedades de novos polímeros a partir de hemicelulose é uma área de atuação pouco explorada, mas alguns trabalhos evidenciam sua potencialidade, como mostra a revisão de Hansen e colaboradores. ${ }^{116}$

Ren e colaboradores ${ }^{117}$ produziram um polímero com característica anfotérica através da esterificação da hemicelulose com agentes catiônicos, que apresentou uma significante degradação da cadeia polimérica e redução da estabilidade térmica em relação ao material de partida. Posteriormente, Ren e colaboradore ${ }^{118}$ efetuaram a carboxilação da hemicelulose utilizando cloroacetato e hidróxido de sódio em meio de água e etanol, obtendo um material com maior estabilidade térmica que a hemicelulose nativa, porém com avançado grau de degradação da cadeia polimérica.

Gabrielii e colaboradores ${ }^{119}$ produziram hidrogéis de hemicelulose com quitosana em meio acidificado. Segundo os autores, as forças coesivas nestes hidrogéis são resultantes do arranjo cristalino dos polímeros e das interações eletrostáticas entre grupos ácidos da hemicelulose e grupos amina da quitosana.

Hartman e colaboradores ${ }^{120}$ desenvolveram um material derivado da hemicelulose com potencialidade para a produção de filmes com capacidade de barreira em relação ao oxigênio, por meio da benzilação da hemicelulose.

\section{Lignina}

O isolamento de lignina das fibras vegetais é dificultado, principalmente, devido às reações de condensação e oxidação que podem ocorrer durante o processo. Todos os processos de extração de lignina levam a algum grau de modificação estrutural que, por consequência, afeta suas propriedades físicas. ${ }^{121}$ Industrialmente, a separação da lignina das fibrilas de celulose é realizada no mesmo processo da polpação, portanto, as características da lignina isolada dependem do processo de deslignificação empregado. ${ }^{122}$

Recentes progressos foram alcançados no isolamento de lignina de fibras vegetais com a acidólise enzimática em condições amenas EMAL (Enzymatic Mild Acidolysis Lignin), a qual produz lignina com características mais próximas às do material em sua forma nativa. ${ }^{123-125}$ Zoia e colaboradores ${ }^{79}$ aperfeiçoaram este método em relação ao rendimento e pureza da lignina, utilizando EMAL combinado com radiação de micro-ondas, em substituição à usual etapa de refluxo durante a acidólise.

A lignina é um material de baixa densidade e abrasividade, com características interessantes para o uso como carga em substituição a cargas inorgânicas. Com certos polímeros, em formulações adequadas, a lignina pode formar compósitos parcial ou até completamente biodegradáveis. ${ }^{126}$ Além disso, em virtude de sua natureza fenólica, espera-se que a lignina aumente a resistência de materiais poliméricos em relação à oxidação, irradiação e exposição a temperaturas elevadas.

Alguns artigos tem sido publicados na literatura, reportando a utilização de lignina como estabilizante para plásticos e borrachas, nos quais a lignina atua como antioxidante ou modificador das propriedades mecânicas. ${ }^{127}$ Fernandes e colaboradores ${ }^{128,129}$ determinaram que blendas de poli(vinil álcool) e lignina Kraft ou derivados de lignina Kraft possuem maior estabilidade térmica em comparação aos componentes puros e, ainda, que a lignina atua como agente antioxidante retardando a foto-oxidação do material quando 
exposto à radiação UV. Geralmente, a incorporação de lignina em materiais termoplásticos é limitada, pois em quantidades elevadas de lignina as blendas se tornam fracas e quebradiças. No entanto, Li e colaboradores ${ }^{130}$ desenvolveram uma blenda homogênea de lignina Kraft com poli(acetato de vinila) e plastificantes, na qual a lignina é o componente principal da blenda com uma concentração de $85 \%$. Os autores determinaram que o comportamento mecânico das blendas está diretamente correlacionado com o grau de associação intrínseco da lignina Kraft.

\section{PREPARAÇÃO E CARACTERIZAÇÃO DE NANOCRISTAIS (NANOWHISKERS) DE CELULOSE}

As regiões amorfas surgem como imperfeições nas microfibrilas de celulose. A razão e as dimensões dos domínios cristalinos e amorfos presentes dependem da origem biológica do material lignocelulósico. As fibrilas de celulose podem ser clivadas transversalmente quando submetidas à hidrólise em meio ácido resultando em pequenos monocristais, partículas altamente cristalinas, que geralmente são denominados de celulose microcristalina ou cristalitos de celulose. ${ }^{131}$ Sob condições controladas, a hidrólise consiste na destruição das regiões amorfas ao redor e entre as microfibrilas de celulose, enquanto os segmentos cristalinos continuam intactos, pois a cinética da hidrólise da região amorfa é mais rápida do que da região cristalina, em virtude da maior permeabilidade da região amorfa. ${ }^{132}$ Na Figura 2 é apresentado um esquema da hidrólise seletiva das fibrilas de celulose que resulta na formação dos nanocristais de celulose. Em geral estes procedimentos levam à formação de suspensões coloidais, sendo o primeiro relato feito por Rånby, ${ }^{133} \mathrm{em} \mathrm{1951,} \mathrm{utilizando} \mathrm{hidrólise}$ com ácido sulfúrico. Posteriormente, em 1962, Battista e Smith ${ }^{134}$ obtiveram uma suspensão estável de celulose microcristalina por meio da hidrólise com ácido clorídrico seguida por desintegração mecânica. Esta descoberta viabilizou a comercialização da celulose microcristalina, que hoje é usada nas indústrias farmacêutica e alimentícia. Além disso, a celulose microcristalina tem demonstrado ser um material estável, fisiologicamente inerte e com alto potencial de aplicação para os mais diversos fins. ${ }^{135,136}$
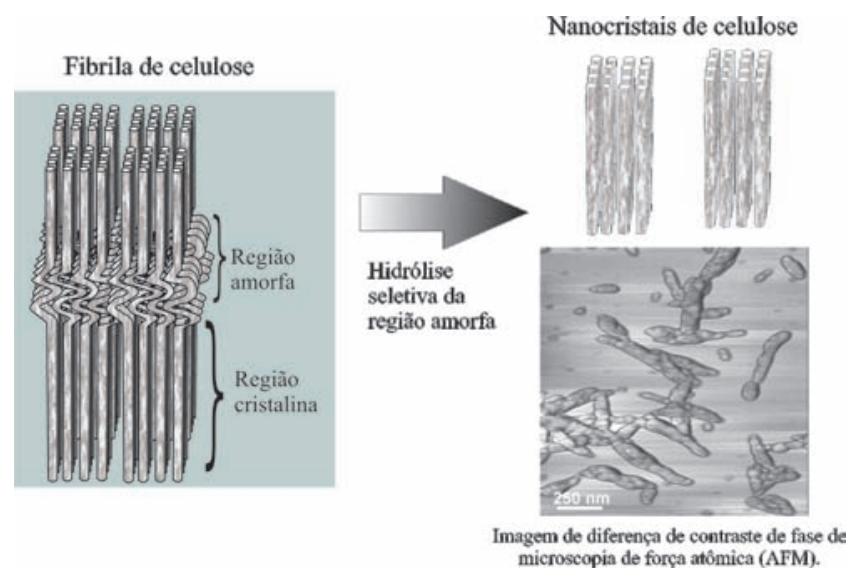

Figura 2. Formação de nanocristais de celulose pela hidrólise seletiva das regiões amorfas das fibrilas de celulose e imagem de diferença de contraste de fase de microscopia de força atômica (AFM). Adaptada da ref. 137

A celulose microcristalina consiste geralmente em uma partícula cilíndrica rígida denominada whisker ${ }^{44,137}$ As partículas cilíndricas rígidas de celulose cristalina com dimensões nanométricas (iguais ou menores que $100 \mathrm{~nm}),{ }^{138}$ os nanowhiskers, com diferentes morfologias e graus de cristalinidade, podem ser obtidas de acordo com a variação da celulose de origem e também das condições de hidrólise. Nos últimos anos, vários grupos de pesquisa têm relatado novas técnicas para a formação de nanocristais de celulose a partir de diferentes fontes naturais ${ }^{139,140}$ e a aplicação destes em materiais poliméricos e compósitos. Os nanocristais de celulose possuem inúmeras vantagens em relação a outros materiais nanoestruturados como, por exemplo, a facilidade no processo de formação, o baixo custo da matéria-prima, as características diversificadas em função do substrato natural de origem e, ainda, as propriedades mecânicas comparadas com as de nanotubos de carbono e de nanofibras inorgânicas. ${ }^{141,142}$

As dependências das características estruturais dos cristais em função da origem podem ser exemplificadas comparando-se as dimensões de cristais de celulose obtidos por processos de hidrólise aná$\operatorname{logos}$, cujas dimensões finais são bem distintas. Elazzouzi-Hafraoui e colaboradores ${ }^{143}$ analisaram as formas e a distribuição de tamanho de nanocristais de celulose obtidos a partir da hidrólise de diferentes espécies de fibras com ácido sulfúrico. Os cristais de celulose obtidos por hidrólise com ácido sulfúrico possuem comprimento e largura de aproximadamente 200 e $5 \mathrm{~nm}$ para o algodão e de $1 \mu \mathrm{m}$ e $15 \mathrm{~nm}$ para os obtidos a partir do tunicata, um animal marinho que se alimenta por filtração e pertence ao filo dos cordados. Na Figura 3 podem ser observadas a micrografia de transmissão e a distribuição de tamanho de nanocristais de celulose obtidos pela hidrólise de fibras de algodão com ácido sulfúrico. ${ }^{143}$

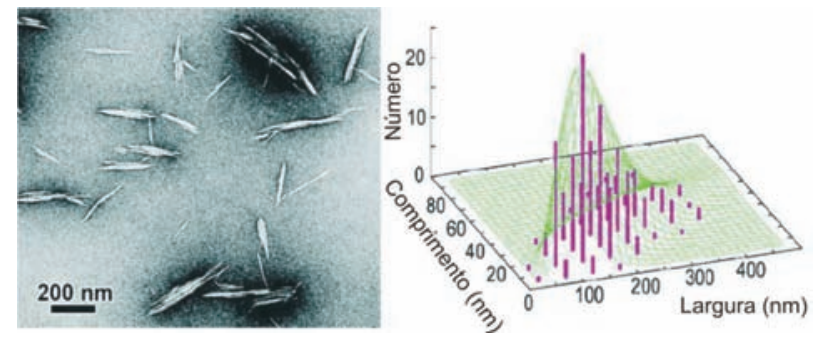

Figura 3. Micrografia de MET e distribuição de tamanho de nanocristais de celulose obtidos pela hidrólise de fibras de algodão utilizando ácido sulfúrico. Adaptada da ref. 143

O efeito das condições de preparo (tempo, temperatura e tratamento com ultrassom) sobre as características estruturais dos cristais de celulose, obtidos a partir do algodão usando ácido sulfúrico, foi avaliado por Dong e colaboradores. ${ }^{144} \mathrm{O}$ prolongamento do tempo de hidrólise causa uma diminuição do comprimento dos cristais de celulose e um aumento na carga superficial, em decorrência do aumento da extensão do processo de sulfonação da superfície dos cristais de celulose.

Desde a década de 1990, há um crescente interesse no uso de celulose microcristalina e whiskers devido a sua aplicabilidade como reforço de matrizes poliméricas, principalmente, em função de sua grande área superficial e ótimas propriedades mecânicas. Assim, diversas metodologias de preparação de whiskers e nanowhiskers têm sido desenvolvidas e otimizadas, já que quanto menor o tamanho da partícula maior o índice de cristalinidade obtido. ${ }^{145,146}$

Recentemente, nanocristais esféricos de celulose com alta polidispersidade foram preparados por Wang e colaboradores, ${ }^{147}$ usando uma mistura de ácido sulfúrico e ácido clorídrico sob irradiação de ultrassom. Essa suspensão dos nanocristais esféricos apresentou propriedades de líquidos cristalinos em elevadas concentrações. Como previsto por Onsager, ${ }^{148}$ os nanocristais de celulose podem sofrer transição de uma fase isotrópica desordenada para uma fase anisotrópica ordenada. A transição de fase depende da forma geométrica dos nanocristais (razão entre comprimento e largura), da densidade de grupos eletricamente carregados na superfície do cristal e da polidispersidade dos cristais. 
Revol e colaboradores ${ }^{149}$ desenvolveram um novo material importante, usando nanocristais de celulose, com propriedades ópticas particulares. Os cristais de celulose solidificados a partir da suspensão apresentaram a capacidade de refletir luz colorida, sendo que o comprimento de onda da luz refletida pode ser ajustado pela força iônica da suspensão. Estes novos materiais têm alta potencialidade para aplicação em papéis de segurança, tal como papel moeda.

\section{Nanocompósitos com nanocristais de celulose}

Os nanocompósitos são obtidos pela incorporação física de nanopartículas de celulose em matrizes poliméricas. As propriedades destes compósitos dependem dos nanocristais de celulose, da matriz polimérica e da interação entre ambos. Tanto os polímeros sintéticos, quanto os naturais, foram utilizados na preparação de nanocompósitos com celulose. Polímeros naturais como o poli(hidroxioctanoato), ${ }^{150-152}$ amido $^{153}$ e seda, ${ }^{154}$ entre outros, foram reforçados com nanocristais de celulose de diferentes origens. Angles e Dufresne ${ }^{155}$ relataram a produção de um material compósito com amido e nanocristais de celulose, obtidos da tunicata, usando glicerol como plastificante. Observaram que ocorre um acúmulo do plastificante na interface entre a celulose e o amido, o que contribui para a dispersão dos nanocristais de celulose no amido.

O trabalho pioneiro de Favier e colaboradores ${ }^{156}$ relatando a utilização de nanocristais de celulose como fase de reforço em polímeros foi um dos fatos que desencadeou o interesse crescente na utilização de cristais de celulose em conjunto com as matrizes poliméricas. Os compósitos são misturas preparadas na tentativa de conciliar as distintas propriedades existentes em diferentes componentes puros ou, então, para aprimorar as características de cada componente em decorrência de interações favoráveis entre os componentes no material compósito. ${ }^{157}$ Dessa forma, os particulados nanométricos, os quais possuem área superficial específica elevada, podem interagir de forma mais efetiva com a fase contínua dos compósitos, o que potencializa os efeitos das interações favoráveis nos nanocompósitos em comparação aos compósitos cujos componentes possuem dimensões micrométricas.

Os polímeros sintéticos utilizados na produção de nanocompósitos com celulose foram poli(estireno-co-butil acrilato), ${ }^{158,159}$ poli(cloreto de vinila), ${ }^{160}$ polipropileno ${ }^{161}$ e epóxi. ${ }^{162}$ Samir e colaboradores ${ }^{163}$ demonstraram a preparação de compósitos de poli(óxido de etileno) e nanocristais de celulose e registraram que a presença dos nanocristais de celulose afetou o processo de cristalização do poli(óxido de etileno) ), e, também, que a formação de esferulitos não foi observada no material compósito. Indicaram, ainda, que a adição dos nanocristais de celulose não comprometeu a capacidade de condução de íons do material, e que aumentou a resistência mecânica do filme.

As técnicas de processamento são um importante fator nas propriedades finais dos nanocompósitos de celulose. ${ }^{164} \mathrm{~A}$ obtenção de compósitos homogêneos é o principal desafio no processo de preparação. A utilização de matrizes hidrossolúveis facilita a formação de compósitos em virtude da alta estabilidade da dispersão coloidal dos nanocristais de celulose em meio aquoso. A utilização de solventes orgânicos, meio hidrofóbico, pode ser também utilizada, mas é necessário o emprego de agentes dispersantes, como surfactantes, ${ }^{165}$ ou de nanocristais de celulose com superfície hidrofobicamente modificada. ${ }^{166-168} \mathrm{~A}$ utilização de nanocristais de celulose com superfícies quimicamente modificadas apresenta maior aplicabilidade do que o simples uso de surfactantes como agentes de dispersão, isso em função da alta área superficial específica dos nanocristais, que exige uma elevada quantidade de surfactante, acarretando prejuízos às propriedades mecânicas dos compósitos formados. ${ }^{169}$

Uma alternativa à dificuldade de dispersão de nanocristais de celulose em solventes orgânicos foi proposta por Noorani e colabo- radores, ${ }^{141}$ que desenvolveram uma metodologia de troca de solvente, possibilitando a formação de dispersões de nanocristais de celulose em N-metil-pirrolidona, que foi posteriormente utilizada para a formação de compósitos com polissulfona. Os compósitos com polissulfona foram testados e apresentaram características ótimas como membranas de biosseparação em sistemas de micro fluidos.

Filmes compósitos de nanocristais de celulose e poliuretanos com propriedades elevadas foram preparados por Cao e colaboradores. ${ }^{170}$ O poliuretano, utilizado como matriz para o compósito, foi preparado usando policaprolactona como pré-polímero. A técnica de formação foi a simples dispersão dos componentes em solução aquosa e a evaporação do solvente. Os resultados da caracterização dos compósitos preparados indicaram que os nanocristais dispersam uniformemente na matriz de poliuretano e que a adição destes causa um significante aumento nos valores do módulo de Young e de resistência à tração dos filmes. Os valores do módulo de Young aumentam de forma exponencial em relação à quantidade de nanocristais adicionados até a razão de $10 \%$ em massa de nanocristais de celulose.

Paralikar e colaboradores ${ }^{171}$ desenvolveram membranas poliméricas com propriedades de barreira ao oxigênio utilizando poli(álcool vinílico) como matriz principal, poli(ácido acrílico) como agente reticulante e nanocristais de celulose. A dispersão dos nanocristais de celulose na matriz polimérica foi analisada utilizando microscopia de luz polarizada. Os resultados indicaram que a dispersão dos nanocristais na matriz polimérica é homogênea para compósitos com concentração de nanocristais de celulose igual ou menor a $10 \%$ em massa. Em compósitos com teor de nanocristais de celulose acima de $10 \%$ em massa ocorre a aglomeração dos nanocristais.

Um compósito elastomérico de alta performace foi preparado por Wu e colaboradores ${ }^{172}$ pela dispersão de nanocristais de celulose em uma matriz de poliuretano. A concentração ótima para as propriedades mecânicas foi de $5 \%$ em massa de celulose em relação à massa do compósito. O compósito contendo $5 \%$ de celulose apresentou resistência à fratura aproximadamente sete vezes maior do que a da matriz polimérica pura. Os autores atribuíram esta melhoria ao efeito sinérgico em função das interações positivas entre os componentes do compósito.

O aumento da resistência mecânica dos compósitos de nanocristais de celulose é evidente, aumenta conforme a quantidade de nanocristais até certo valor que, na maioria dos sistemas, está em torno de $10 \%$ em massa. Esta quantidade máxima está relacionada à dispersão do sistema. A aglomeração dos nanocristais em concentrações acima de $10 \%$ em massa causa a separação de fase no compósito, o que compromete as propriedades mecânicas do material. Assim, a formação de compósitos com alto teor de nanocristais de celulose com distribuição homogênea é altamente desejável, mas metodologias inovadoras devem ser desenvolvidas para esta finalidade.

As técnicas de polimerização a partir da superfície ou a formação de ligações covalentes entre a matriz polimérica e os nanocristais podem ser alternativas à dificuldade de dispersão dos nanocristais de celulose. Neste sentido, Goetz e colaboradores ${ }^{173}$ prepararam um compósito com poli(metil-vinil-éter-co-ácido malêico), poli(etileno glicol) e nanocristais de celulose. A formação de grupos ésteres entre a matriz polimérica e os nanocristais de celulose aumenta a interação entre os componentes do compósito, possibilitando a adição de maiores teores de nanocristais de celulose. Os compósitos assim preparados apresentaram capacidade de retenção de água de até nove vezes o seu peso seco, podendo ser classificados como hidrogéis.

A enxertia por ligações covalentes de polímeros em nanocristais de celulose foi demonstrada por Xu e colaboradores, ${ }^{174}$ que realizaram a imobilização de um iniciador de polimerização radicalar por transferência de átomos ATRP (Atom Transfer Radical Polymerization) na superfície de nanocristais de celulose e, a partir destes, demonstraram 
o crescimento de cadeias de um polímero vinílico com um grupo azo pendente. As técnicas de enxertia para a formação de compósitos, a partir de superfícies, são promissoras devido à possibilidade de polimerização de diferentes monômeros ou à possibilidade de formação de copolímeros. ${ }^{175}$

\section{BIOCOMPÓSITOS: FIBRAS LIGNOCELULÓSICAS E POLÍMEROS BIODEGRADÁVEIS}

A história de plásticos reforçados com fibras começou no início do século XX com a utilização de celulose em resinas fenólicas, mas ganhou status de commodity com a utilização de fibras inorgânicas, fibras de vidro, em matrizes poliméricas de ureia e melamina. Hoje em dia, a indústria dos polímeros reforçados com fibras é um negócio que movimenta bilhões de dólares ao redor do mundo. ${ }^{176}$ Nas últimas décadas, a utilização de fibras naturais como reforços tem ganhado a atenção da comunidade científica e das indústrias, como alternativa às fibras inorgânicas, com inúmeras vantagens.

As pesquisas em compósitos com fibras naturais baseados no tipo de polímero utilizado como matriz podem ser divididas em duas classes, podendo ser compósitos de fibras naturais/ plásticos e compósitos "verdes". ${ }^{177,178}$ Os compósitos de fibras naturais/ plásticos são produzidos pela união de fibras naturais e polímeros não-biodegradáveis, sendo principalmente os derivados de petróleo, enquanto os compósitos verdes são preparados utilizando polímeros naturais biodegradáveis, principalmente polissacarídeos e poli-hidroxialcanoatos. Os poli-hidroxialcanoatos são poliésteres alifáticos que, ao contrário dos poliésteres aromáticos, são considerados biodegradáveis. ${ }^{179}$

Ambos os tipos de compósitos apresentam fatores que os tornam ambientalmente corretos. Os compósitos de fibras naturais/plásticos podem ser preparados como uma alternativa ao descarte de polímeros não biodegradáveis, como uma forma de reciclagem, atribuindo novas funções a polímeros com propriedades inferiores, se comparados ao polímero virgem de origem. Os compósitos de fibras naturais/plásticos não podem ser considerados biodegradáveis, no entanto, sua biodegradabilidade é aumentada em virtude da presença da fibra natural. ${ }^{144} \mathrm{Uma}$ ótima revisão de plásticos reforçados com fibras naturais foi elaborada por Bledzki e Gassan, ${ }^{180}$ na qual foram discutidos os aspectos químicos e físicos que influenciam a qualidade dos compósitos.

A maior atenção deve ser direcionada aos compósitos verdes, pois estes são totalmente biodegradáveis, logo, ao final de sua vida útil, podem ser facilmente descartados sem que haja prejuízo ambiental. Os esforços atuais tem sido focados na preparação de compósitos verdes com propriedades avançadas, cujo processamento não inviabilize sua produção em larga escala.

Placktt e colaboradores ${ }^{181}$ utilizaram L-poli(ácido lático) combinado às fibras de juta para formar compósitos na forma de filmes por uma técnica de empilhamento. Os resultados obtidos na caracterização do material sugerem que o processamento causou apenas uma leve diminuição na massa molar média do L-poli(ácido lático). No entanto, as propriedades mecânicas dos compósitos foram superiores às do polímero puro, mesmo com a existência de poros distribuídos por todo o compósito, como observado por microscopia eletrônica.

Compósitos verdes constituídos de fibras de celulose e poliésteres biodegradáveis (poli(hidroxibutirato-co-valerato), poli(succinato de butileno) e poli(ácido lático)) foram preparados e caracterizados por Shibata e colaboradores ${ }^{182}$. Os módulos de tensão e a resistência mecânica de todos os compósitos preparados são maiores do que os dos polímeros puros. O teste de biodegradabilidade demonstrou que o compósito de fibras de celulose e poli(ácido lático) foi quase que totalmente degradado em 120 dias, enquanto no mesmo período de tempo não foram verificados sinais de degradação do poli(ácido lático) puro.
A modificação da superfície de materiais é uma maneira de alterar as propriedades de superfície sem que haja alterações drásticas nas propriedades de seu volume. ${ }^{183,184} \mathrm{Na}$ formação de compósitos, as modificações de superfícies são realizadas nas fibras lignocelulósicas na intenção de melhorar a compatibilidade com a matriz polimérica.

A formação de compósitos verdes encontra, em muitos casos, dificuldades em relação à adesão entre as fibras lignocelulósicas e os polímeros naturais. Na tentativa de melhorar esta adesão nos compósitos verdes, Pommet e colaboradores ${ }^{185}$ propuseram uma forma de modificar a superfície do material lignocelulósico pela utilização de uma bactéria. A bactéria utilizada produz e deposita celulose na superfície das fibras lignocelulósicas, mudando as características superficiais e proporcionando uma melhoria na compatibilidade dessas fibras lignocelulósicas com diferentes polímeros naturais.

\section{CONCLUSÃO}

Segundo a literatura, o Brasil se destaca mundialmente pela produção de compósitos utilizando fibras vegetais, principalmente, destinadas ao setor automobilístico. O setor de fibras lignocelulósicas está em expansão incentivada pela injeção de recursos de algumas das grandes empresas nacionais devido à busca pela sustentabilidade, principalmente, no setor do WPC. Esse crescimento pode ser catalisado por uma melhor divulgação dos benefícios da utilização das fibras lignocelulósicas, por ações governamentais de incentivo ao setor e, principalmente, pela formação de parcerias entre universidades e empresas, o que geraria maior número de publicações científicas e, consequentemente, patentes e exportação de tecnologia.

Neste sentido, ações como a da ONU, que declarou o ano de 2009 como o ano internacional das fibras naturais, são úteis para alavancar a exploração real das fibras naturais. Cabe aos pesquisadores um maior empenho voltado ao desenvolvimento de pesquisas que viabilizem novos produtos, a partir de biomassa, com alto valor agregado e que contribuam para a sustentabilidade.

Os trabalhos futuros envolvendo fibras lignocelulósicas devem explorar as características únicas destes materiais como, por exemplo, o arranjo cristalino das microfibrilas de celulose. A utilização dos componentes isolados gera inúmeras possibilidades de aplicação, em virtude das diferenças químicas e estruturais dos componentes chaves das fibras lignocelulósicas. Nesta área de pesquisa, os desafios são o desenvolvimento de processos para a separação e modificações dos componentes chaves das fibras lignocelulósicas, evitando a degradação das cadeias poliméricas dos constituintes principais. A realização de modificações químicas durante o processo de separação pode ser uma alternativa, pois reduz a exposição da matéria-prima. Novas oportunidades de pesquisa na área de modificação e aplicações dos componentes isolados das fibras lignocelulósicas podem ser alavancadas pelo uso de meios reacionais diferenciados como os líquidos iônicos, os ambientes miscelares ou os fluidos supercríticos.

A utilização de nanocristais de celulose como nanorreforço em compósitos ou em aplicações de maior complexidade é um assunto que gera interesse substancial, principalmente porque estes nanocristais podem ser fabricados de forma fácil e rápida empregando-se matérias-primas abundantes ao redor do mundo. A maior dificuldade na incorporação dos nanocristais de celulose aos compósitos está relacionada à aglomeração das partículas em concentrações superiores a $10 \%$ em massa de nanocristais. Em decorrência da baixa compatibilidade das matrizes poliméricas com a celulose, o que poderá ser superado com o desenvolvimento de técnicas de modificações de superfície dos nanocristais de celulose. Novos esforços devem ser direcionados para o desenvolvimento de metodologias de hidrólise sem a presença de ácido sulfúrico, para evitar o processo de sulfonação das superfícies dos nanocristais de celulose, o que 
dificulta as dispersões em polímeros apolares e atrapalha as reações de modificação de superfície.

\section{REFERÊNCIAS}

1. Partain, E. M. Em Industrially Important Polysaccharides; Craver, C. D.; Carraher Jr, C. E., eds.; Applied Polymer Science 21st Century; $1^{\text {st }}$ ed., Elsevier Science Ltd., 2000.

2. Jegatheesan, V.; Liow, J. L.; Shu, L.; Kim, S. H.; Visvanathan, C.; Journal of Cleaner Production (2009), doi:10.1016/j.jclepro.2008.11.016

3. Kirchhoff, M. M.; Resources, Conservation and Recycling 2005, 44, 237.

4. Warner, J. C.; Cannon, A. S.; Dye, K. M.; Environmental Impact Assessment Review 2004, 24, 775.

5. Mattoso, L. H. C.; Pereira, N. C.; Souza, M. L.; Agnelli, J. A. M. Em O Agro Negócio do Sisal no Brasil; Silva, O. R. R. F.; Beltrão, N. E. D. M., eds.; 1ª ed., EMBRAPA: Brasília, 1999.

6. Lucas, N.; Bienaime, C.; Belloy, C.; Queneudec, M.; Silvestre, F.; NavaSaucedo, J.-E.; Chemosphere 2008, 73, 429.

7. Shah, A. A.; Hasan, F.; Hameed, A.; Ahmed, S.; Biotechnol. Adv. 2008, 26, 246.

8. Leadbitter, J.; Prog. Polym. Sci. 2002, 27, 2197.

9. Packham, D. E.; Int. J. Adhes. Adhes. 2009, 29, 248.

10. Le Duigou, A.; Pillin, I.; Bourmaud, A.; Davies, P.; Baley, C.; Composites Part A 2008, 39, 1471.

11. Siracusa, V.; Rocculi, P.; Romani, S.; Rosa, M. D.; Trends Food Sci. Technol. 2008, 19, 634.

12. Strange, M.; Plackett, D.; Kaasgaard, M.; Krebs, F. C.; Sol. Energy Mater. Sol. Cells 2008, 92, 805.

13. Siddique, R.; Khatib, J.; Kaur, I.; Waste Manage. 2008, 28, 1835.

14. Bordes, P.; Pollet, E.; Avérous, L.; Prog. Polym. Sci. 2009, 34, 125.

15. Huang, X.; Netravali, A.; Composites Science and Technology (2009), doi: 10.1016/j.compscitech.2009.01.014.

16. Okubo, K.; Fujii, T.; Thostenson, E. T.; Composites Part A (2009), doi: 10.1016/j.compositesa.2009.01.012.

17. Satyanarayana, K. G.; Arizaga, G. G. C.; Wypych, F.; Progress in Polymer Science (2008), doi:10.1016/j.progpolymsci.2008.12.002.

18. Effendi, A.; Gerhauser, H.; Bridgwater, A. V.; Renew. Sustain. Energ. Rev. 2008, 12, 2092.

19. Vila, C.; Campos, A. R.; Cristovão, C.; Cunha, A. M.; Santos, V.; Parajó, J. C.; Compos. Sci. Techol. 2008, 68, 944.

20. Nechwatal, A.; Mieck, K. P.; Reussmann, T.; Compos. Sci. Techol. 2003, 63, 1273.

21. Balzer, P. S.; Vicente, L. L.; Briesemeister, R.; Becker, D.; Sordi, V.; Rodolfo Jr, A.; Feltran, M. B.; Polímeros: Ciência e Tecnologia 2007, $17,1$.

22. Mishra, S.; Mohanty, A. K.; Drzal, L.T.; Misra, M.; Hinruchsen, G.; Macromol. Mater. Eng. 2004, 289, 955.

23. http://www.fao.org.br, acessada em Fevereiro 2009.

24. http://www.agricultura.gov.br, acessada em Fevereiro 2009.

25. Satyanarayana, K. G.; Guimarães, J. L.; Wypych, F.; Composites Part A 2007, 38, 1694.

26. Demirbas, A.; Energy Convers. Manage. 2008, 49, 2106.

27. Lora, E. S.; Andrade, R. V.; Renewable and Sustainable Energy Reviews (2008), doi:10.1016/j.rser.2007.12.004.

28. Albuquerque, M. C. G.; Machado, Y. L.; Torres, A. E. B.; Azevedo, D. C. S.; Cavalcante Jr., C. L.; Firmiano, L. R.; Parente Jr., E. J. S.; Renew. Energy 2009, 34, 857.

29. Escobar, J. C.; Lora, E. S.; Venturini, O. J.; Yáñez, E. E.; Castillo, E. F.; Almazan, O.; Renewable and Sustainable Energy Reviews (2008), doi:10.1016/j.rser.2008.08.014.

30. http://www.reciclaveis.com.br/noticias/00805/0080513recursos.htm, acessada em Fevereiro 2009.
31. Cardoso, A. A.; Machado, C. M. D.; Pereira, E. A.; Química Nova na Escola 2008, n $28,9$.

32. Nunes, A. A.; Franca, A. S.; Oliveira, L. S.; Bioresour. Technol. 2009, 100, 1786.

33. Karagöz, S.; Tay, T.; Ucar, S.; Erdem, M.; Bioresour. Technol. 2008, 99, 6214.

34. Garg, U.; Kaur, M .P., Jawa, G. K.; Sud, D.; Garg, V. K.; J. Hazard. Mater. 2008, 154, 1149.

35. Garg, U.; Kaur, M. P.; Garg, V. K.; Sud, D.; J. Hazard. Mater. 2007, 140, 60.

36. Kaikake, K.; Hoaki, K.; Sunada, H.; Dhakal, R. P.; Baba, Y.; Bioresour. Technol. 2007, 98, 2787.

37. Boucher, J.; Steiner, Z.; Marison, I. W.; Water Res. 2007, 41, 3209.

38. Tan, I. A. W.; Hameed, B. H.; Ahmad, A. L.; Chem. Eng. J. 2007, 127, 111.

39. Crini, G.; Bioresour. Technol. 2006, 97, 1061.

40. Santos, A. M.; Dissertação de Mestrado, Universidade Federal do Paraná, Brasil, 2006.

41. Joshi, S. V.; Drzal, L.T.; Mohanty, A. K.; Arora, S.; Composites Part A 2004, 35, 371.

42. Gomes, A.; Matsuo, T.; GodaJ, K.; Ohgi, J.; Composites Part A 2007, $38,1811$.

43. Araújo, J. R.; Waldman, W. R.; De Paoli, M. A.; Polym. Degrad. Stab. 2008, 93, 1770.

44. John, M. J.; Thomas, S.; Carbohydr. Polym. 2008, 71, 343.

45. Pervaiz, M.; Sain, M. M. ; Resour. Conservat. Recycl. 2003, 39, 325.

46. http://www.cnpat.embrapa.br, acessada em Março 2009.

47. http://www.poematec.com.br, acessada em Março 2009.

48. http://www.gazetamercantil.com.br, (nota "Poematec vai produzir bancos de carros da Volks" publicada na web em 16/07/2004) acessada em Março 2009.

49. http://www.braziliansisal.com; acessada em Março 2009.

50. Rodolfo Jr., A.; John, V. M.; Polímeros 2006, 16, 1.

51. Correa, C. A.; Fonseca, C. N. P.; Neves, S.; Razzino, C. A.; Hage Jr., E.; Polímeros 2003, 13, 154.

52. http://www.simplas.com.br/pdf_ai/img/INFOPLAS_n38_dezembro_2008.pdf, acessada em Fevereiro 2009.

53. Yu, Y.; Lou, X.; Wu, H.; Energy Fuels 2008, 22, 46.

54. Jayaraman, K.; Compos. Sci. Techol. 2003, 63, 367.

55. Mohan, D.; Pittman, C. U.; Steele, P. H.; Energy Fuels 2006, $20,848$.

56. Rogalinski, T.; Ingram, T.; Brunner, G.; J. Supercrit. Fluids 2008, 47, 54.

57. Pietak, A.; Korte, S.; Tan, E.; Downard, A.; Staiger, M. P.; Appl. Surf. Sci. 2007, 253, 3627.

58. Ren, J.-L.; Sun, R.-C.; Peng, F.; Polym. Degrad. Stab. 2008, 93, 786.

59. Gabrielii, I.; Gatenholm, P.; Glasser, W. G.; Jain, R. K.; Kenne, L.; Carbohydr. Polym. 2002, 43, 367.

60. Yang, B.; Wyman, C. E.; Bioresour. Technol. 2008, 99, 5756.

61. John, M. J.; Thomas, S.; Carbohydr. Polym. 2008, 71, 343.

62. Brasileiro, L. B.; Colodette, J. L.; Piló-Veloso, D.; Quim. Nova 2001, 24, 819.

63. Baptista, C.; Robert, D.; Duarte, A. P.; Bioresour. Technol. 2008, 99, 2349.

64. Byrd, M. V.; Gratzl, J. S.; Singh, R. P.; Tappi J. 1992, 75, 207.

65. Vázquez, G.; González-Álvarez, J.; Rodríguez, E. M.; Freire, S.; Antorrena, G.; Bioresour. Technol. 2002, 81, 141.

66. García-Cubero, M. T.; González-Benito, G.; Indacoechea, I.; Coca, M.; Bolado, S.; Bioresour. Technol. 2009, 100, 1608.

67. Huang, G.-L.; Shi, J. X.; Langrish, T. A. G.; Journal of Cleaner Production 2008, 16, 1287.

68. Abou-Yousef, H.; El-Sakhawy, M.; Kamel, S.; Ind. Crops Prod. 2005, $21,337$.

69. Teixeira, L. C.; Linden, J. C.; Schroeder, H. A.; Renew. Energy 1999, 16,1070 . 
70. Jiménez, L.; Ramos, E.; De la Torre, M. J.; Pérez, I.; Ferrer, J. L.; Bioresour. Technol. 2008, 99, 1474.

71. Khristova, P.; Kordsachia, O.; Patt, R.; Karar, I.; Khider, T.; Ind. Crops Prod. 2006, 23, 131.

72. Castellan, A.; Da Silva Perez, D.; Nourmamode, A.; Grelier, S.; Terrones, M. G. H.; Machado, A. E. H.; Ruggiero, R.; J. Braz. Chem. Soc. 1999, 10, 197.

73. Sun, J. X.; Sun, X. F.; Zhao, H.; Sun, R. C.; Polym. Degrad. Stab. 2004, $84,331$.

74. Hendriks, A. T. W. M.; Zeeman, G.; Bioresour. Technol. 2009, 100, 10.

75. Ramos, L. P.; Quim. Nova 2003, 26, 863.

76. Rebenfeld, L. Em Fibers; Craver, C. D.; Carraher Jr, C. E., eds.; Applied Polymer Science 21st Century. First Edition, Elsevier Science Ltd, 2000.

77. Uragami, T.; Ohsumi, Y.; Sugihara, M.; Polymer 1982, 23, 999.

78. Laity, P. R.; Glover, P. M.; Godward, J.; McDonald, P. J.; Hay, J. N.; Cellulose 2000, 7, 227

79. Zoia, L.; Orlandi, M.; Argyropoulos, D. S.; J. Agric. Food Chem. 2008, $56,10115$.

80. Simon, J.; Miller, H. P.; Koch, R.; Miiller, V.; Polym. Degrad. Stab. 1998, 59, 107.

81. Heinze, T.; Liebert, T.; Macromol. Symp. 2004, 208, 167.

82. Barsbay, M.; Guven, G.; Stenzel, M. H.; Davis, T. P.; Barner-Kowollik, C.; Barner, L.; Macromolecules 2007, 40, 7140.

83. Mauricio, M. R.; Carvalho, G. M.; Radovanovic, E.; Muniz, E. C.; Rubira, A. F.; Mater. Sci. Eng. C 2009, 29, 594.

84. Számel, G.; Domján, A.; Klébert, S.; Pukánszky, B.; Eur. Polym. J. 2008, 44, 357.

85. Számel, G.; Klebert, S.; Sajo, I.; Pukanszky, B.; J. Therm. Anal. Cal. 2008, 91,715 .

86. Hatakeyama, H.; Yoshida, T.; Hatakeyama, T.; J. Therm. Anal. Cal. 2000, 59, 157.

87. Heinze, T.; Liebert, T.; Prog. Polym. Sci. 2001, 26, 1689.

88. Hoenich, N. A.; Woffindin, C.; Stamp, S.; Roberts, S. J.; Turnbull, J.; Biomaterials 1997, 18, 1299

89. Burger, J.; Kettenbach, G.; Klufers, P.; Macromol. Symp. 1995, 99, 113.

90. Liebert, T.; Heinze, T.; Macromol. Symp. 1998, 130, 270.

91. Saalwachter, K.; Burchard, W.; Klufers, P.; Kettenbach, G.; Mayer, P.; Klemm, D.; Dugarmaa, S.; Macromolecules 2000, 33, 4094.

92. Isogai, A.; Atalaia, R. H.; Cellulose 1998, 5, 309.

93. Heinze, T.; Pfeiffer, K.; Angew. Makromol. Chem. 1999, $266,37$.

94. Fischer, S.; Voigt, W.; Fisher, K.; Cellulose 1999, 6, 213.

95. Leipner, H.; Fischer, S.; Breder, E.; Voigt, W.; Macromol. Chem. Phys. 2000, 201, 2041.

96. Michael, M.; Ibbett, R. N. e Howarth, O. W.; Cellulose 2000, 7, 21.

97. Cai, J.; Zhang, L.; Biomacromolecules 2006, 7, 183.

98. Cai, J.; Zhang, L.; Chang, C.; Cheng, G.; Chen, X.; Chu, B.; Chem. Phys. Chem. 2007, 8, 1572.

99. Ruan, D.; Zhang, L.; Mao, Y.; Zeng, M.; Li, X.; J. Membr. Sci. 2004, 241, 265.

100. Cai, J.; Zhang, L.; Macromol. Biosci. 2005, 5, 539.

101. Qi, H.; Chang, C.; Zhang, L.; Cellulose 2008, 15, 779.

102. Cai, J.; Zhang, L.; Zhou, J.; Qi, H.; Chen, H.; Kondo, T.; Chen, X.; Chu, B.; Adv. Mater. 2007, 19, 821.

103. Mao, Y.; Zhou, J.; Cai, J.; Zhang, L.; J. Membr. Sci. 2006, 279, 246.

104. Rahn, K.; Diamantoglou, M.; Berghmans, H.; Heinze, T.; Angew. Makromol. Chem. 1996, 238, 143.

105. Hagiwara, I.; Shiraishi, N.; Yokota, T.; J. Wood Chem. Technol. 1981, 1, 93.

106. Isogai, A.; Ishizu, A.; Nakano, J.; J. Appl. Polym. Sci. 1984, 29, 2097.

107. Isogai, A.; Ishizu, A.; Nakano, J.; J. Appl. Polym. Sci. 1987, 33, 1283.
108. Zhu, S.; Wu, Y.; Chen, Q.; Yu, Z.; Wang, C.; Jin, S.; Ding, Y.; Wu, G.; Green Chem. 2006, 8, 325.

109. Zhang, H.; Wu, J.; Zhang, J.; He, J.; Macromolecules 2005, 38, 8272.

110. Heinze, T.; Schwikal, K.; Barthel, S.; Macromol. Biosci. 2005, 5, 520.

111. Kosan, B.; Michels, C.; Meister, F.; Cellulose 2008, 15, 59.

112. Granström, M.; Kavakka, J.; King, A.; Majoinen, J.; Mäkelä, V.; Helaja, J.; Hietala, S.; Virtanen, T.; Maunu, S.-L.; Argyropoulos, D. S.; Kilpeläinen, I.; Cellulose 2008, 15, 481.

113. Feng, L.; Chen, Z.-L.; J. Mol. Liq. 2008, 142, 1.

114. Teleman, A.; Harjunpaa, V.; Tenkanen, M.; Buchert, J.; Hausalo, T.; Drakenberg, T.; Vuorinen, T.; Carbohydr. Res. 1995, 272, 55.

115. Thomsen, M. H.; Thygesen, A.; Thomsen, A. B.; Bioresour. Technol. 2008, 99, 4221.

116. Hansen, N. M. L.; Plackett, D.; Biomacromolecules 2008, 9, 6.

117. Ren, J.-L.; Sun, R.-C.; Liu, C. F.; Chao, Z.Y.; Luo, W.; Polym. Degrad. Stab. 2006, 91, 2579.

118. Ren, J.-L.; Sun, R.-C.; Peng, F.; Polym. Degrad. Stab. 2008, 93, 786.

119. Gabrielii. I.; Gatenholm, P.; Glasser, W.G.; Jain, R. K.; Kenne, L.; Carbohydr. Polym. 2000, 43, 367.

120. Hartman, J.; Albertsson, A.-C.; Sjöberg, J.; Biomacromolecules 2006, 7, 1983.

121. Pasquini, D.; Balogh, D. T.; Antunes, P. A.; Constantino, C. J. L.; Curvelo, A. A. S.; Aroca, R. F.; Oliveira, O. N.; Langmuir 2002, 18, 6593.

122. Lin, S. Y.: Lebo Jr., S. E.; Encyclopedia of chemical technology, $1^{\text {st }}$ ed., Wiley: New York, 1995, vol. 4.

123. Guerra, A.; Filpponen, I.; Lucia, L. A.; Argyropoulos, D. S.; J. Agric. Food Chem. 2006, 54, 9696.

124. Guerra, A.; Gaspar, A. R.; Contreras, S.; Lucia, L. A.; Crestini, C.; Argyropoulos, D. S.; Phytochemistry 2007, 68, 2570.

125. Guerra, A.; Norambuena, M.; Freer, J.; Argyropoulos, D. S.; J. Nat. Prod. 2008, 71, 836.

126. Alexy, P.; Kosikova, B.; Podstranka, G.; Polymer 2000, 41, 4901.

127. Glasse, W. G. Em Lignin in Pulp and Paper: Chemistry and Chemical Technology; Casey, J. P., ed.; $3^{\text {rd }}$ ed., John Willey \& Sons: New York, 1980, Vol. I, p. 39.

128. Fernandes, D. M.; Hechenleitner, A. A. W.; Pineda, E. A. G.; Thermochim. Acta 2006, 441, 101.

129. Fernandes, D. M.; Hechenleitnera, A. A.W.; Jobb, A. E.; Radovanocic, E.; Pineda, E. A. G.; Polym. Degrad. Stab. 2006, 91, 1192.

130. Li, Y.; Mlynár, J.; Sarkanen, S.; J. Polym. Sci.- Polym. Chem. 1998, 35, 1899.

131. Braun, B.; Dorgan, J. R.; Chandler, J. P.; Biomacromolecules 2008, 9 , 1255.

132. Samir, M. A. S.; Alloin, F.; Dufresne, A.; Biomacromolecules 2005, 6 , 612.

133. Rånby, B. G.; Discuss. Faraday Soc. 1951, 11,158.

134. Battista, O. A.; Smith, P. A.; Ind. Eng. Chem. Res. 1962, 54, 20.

135. Uesu, N. Y.; Pineda, E. A. G.; Hechenleitner, A. A.W.; Int. J. Pharm. 2006, 206, 85.

136. Sturcova, A.; Davies, G. R.; Eichhorn, S. J.; Biomacromolecules 2005, $6,1055$.

137. Kvien, I.; Tanem, B. S.; Oksman, K.; Biomacromolecules 2005, 6, 3160.

138. Filson, P. B.; Dawson-Andoh, B. E.; Bioresour. Technol. 2009, 100, 2259.

139. Heux, L.; Dinand, E.; Vignon, M. R.; Carbohydr. Polym. 1999, 40, 115.

140. Samir, M. A. S. A.; Alloin, F.; Paillet, M.; Dufresne, A.; Macromolecules 2004, 37, 4313.

141. Noorani, S.; Simonsen, J.; Atre, S.; Cellulose 2007, 14, 577.

142. Sturcova, A.; Davies, G. R.; Eichhorn, S. J.; Biomacromolecules 2005, 6, 1055.

143. Elazzouzi-Hafraoui, S.; Nishiyama, Y.; Putaux, J.-L.; Heux, L.; Dubreuil, F.; Rochas, C.; Biomacromolecules 2008, 9, 57. 
144. Dong, X. M.; Revol, J.-F. O.; Gray, D. G.; Cellulose 1998, 5, 19.

145. Bondeson, D.; Mathew, A.; Oksman, K.; Cellulose 2006, 13, 171.

146. Bonini, C.; Heux, L.; French Patent FR 99.07493, 2000.

147. Wang, N.; Ding, E.; Cheng, R.; Langmuir 2008, 24, 5.

148. Onsager, L.; Ann. N. Y. Acad. Sci. 1949, 51, 627.

149. Revol, J. F.; Godbout, L.; Gray, D.; U.S. Patent 5,629,055, 1997.

150. Dubief, D.; Samain, E.; Dufresne, A.; Macromolecules 1999, 32, 5765.

151. Dufresne, A.; Kellerhals, M. B.; Witholt, B.; Macromolecules 1999, 32, 7396.

152. Dufresne, A.; Compos. Interfac. 2003, 10, 369.

153. Angles, M. N.; Dufresne, A.; Macromolecules 2000, 33, 8343.

154. Noshiki, Y.; Nishiyama, Y.; Wada, M.; Kuga, S.; Magoshi, J.; J. Appl. Polym. Sci. 2002, 86, 3425.

155. Angles, M. N.; Dufresne, A.; Macromolecules 2001, 34, 2921.

156. Favier, V.; Canova, G. R.; Cavaillé, J.-Y.; Chanzy, H.; Dufresne, A.; Gauthier, C.; Polym. Adv. Technol. 1995, 6, 351.

157. Silva, R.; Kunita, M. H.; Girotto, E. M.; Radovanovic, E.; Muniz, E. C.; Carvalho, G. M.; Rubira, A. F.; J. Braz. Chem. Soc. 2008, 19, 1224.

158. Favier, F.; Chanzy, H.; Cavaillé, J.-Y.; Macromolecules 1995, 28, 6365.

159. Helbert, W.; Cavaillé, J.-Y.; Dufresne, A.; Polym. Compos. 1996, 17, 604

160. Chazeau, L.; Cavaillé, J. -Y.; Canova, G.; Dendievel, R.; Boutherin, B.; J. Appl. Polym. Sci. 1999, 71, 1797.

161. Ljungberg, N.; Bonini, C.; Bortolussi, F.; Boisson, C.; Heux, L.; Cavaille, J. Y. ; Biomacromolecules 2005, 6, 2732.

162. Ruiz, M.; Cavaillé, J.-Y.; Dufresne, A.; Graillat, C.; Gérard, J.-F. ; Macromol. Symp. 2001, 169, 211.

163. Samir, M. A. S. A.; Chazeau, L.; Alloin, F.; Cavaille, J. Y.; Dufresne, A.; Sanchez, J. Y.; Electrochim. Acta 2005, 50, 3897.

164. Cavaillé, J. Y.; Dufresne, A.; Paillet, M.; Azizi Samir, M. A. S.; Alloin, F.; Sanchez, J. Y.; French Patent FR2841255, 1999.
165. Bonini, C.; Heux, L.; Cavaille, J. Y.; Lindner, P.; Dewhurst, C.; Terech, P.; Langmuir 2002, 18, 3311.

166. Araki, J.; Wada, M.; Kuga, S.; Langmuir 2001, 17, 21.

167. Goussé, C.; Chanzy, H.; Exoffier, G.; Soubeyand, L.; Fleury, E.; Polymer 2002, 43, 2645.

168. Grunert, M.; Winter, W. T.; Polym. Mater. Sci. Eng. 2002, 86, 367.

169. Samir, M. A. S. A.; Alloin, F.; Dufresne, A.; Biomacromolecules 2005 , 6,612 .

170. Cao, X.; Dong, H.; Li, C. M.; Biomacromolecules 2007, 8, 899.

171. Paralikar, S. A.; Simonsen, J.; Lombardi, J.; J. Membr. Sci. 2008, 320, 248 .

172. Wu, Q.; Henriksson, M.; Liu, X.; Berglund, L. A.; Biomacromolecules 2007, 8, 3687.

173. Goetz, L.; Mathew, A.; Oksman, K.; Gatenholm, P.; Ragauskas, A. J.; Carbohydr. Polym. 2009, 75, 85.

174. Xu, Q.; Yi, J.; Zhang, X.; Zhang, H.; Eur. Polym. J. 2008, 44, 2830.

175. Silva, R.; Muniz, E. C.; Rubira, A. F.; Langmuir 2009, 25, 873.

176. John, M. J.; Thomas, S.; Carbohydr. Polym. 2008, 71, 343.

177. Šimkovic, I.; Carbohydr. Polym. 2008, 74, 759.

178. Beg, M. D. H.; Pickering, K. L.; Polym. Degrad. Stab. 2008, 93, 1939.

179. Silva, R.; Carvalho, G. M.; Muniz, E. C.; Rubira, A. F.; e-Polymers 2007, 134, 1

180. Bledzki, A. K.; Gassan, J.; Prog. Polym. Sci. 1999, 24, 221.

181. Plackett, D.; Andersen, T. L.; Pedersen, W. B.; Nielsen, L.; Compos. Sci. Techol. 2003, 63, 1287.

182. Shibata, M.; Oyamada, S.; Kobayashi, S.; Yaginuma, D.; J. Appl. Polym. Sci. 2004, 92, 3857.

183. Silva, R.; Muniz, E. C.; Rubira, A. F.; Polymer 2008, 49, 4066.

184. Silva, R.; Muniz, E. C.; Rubira, A. F.; Appl. Surf. Sci. 2009, 255, 6345.

185. Pommet, M.; Juntaro, J.; Heng, J. Y. Y.; Mantalaris, A.; Lee, A. F.; Wilson, K.; Kalinka, G.; Shaffer, M. S. P.; Bismarck, A.; Biomacromolecules 2008, 9, 1643. 